\title{
Sterically Hindered Elementary Reactions in Radical Polymerization of $\alpha$-Ethylacrylic Esters as Studied by ESR Spectroscopy
}

\author{
Seiya Kobatake and Bunichiro Yamada* \\ Material Chemistry Laboratory, Faculty of Engineering, Osaka City University, \\ Sugimoto, Sumiyoshi-ku, Osaka 558, Japan
}

(Received November 24, 1995)

\begin{abstract}
Radical polymerizations of methyl $\alpha$-ethylacrylate (MEA) and cyclohexyl $\alpha$-ethylacrylate (CHEA) in bulk were kinetically investigated on the basis of the absolute rate constants of elementary reactions evaluated by ESR spectroscopy. ESR spectra of the propagating radicals from MEA and CHEA were observed as five-line spectra by accumulation of a few scans during the slow polymerization of MEA and CHEA to low molecular weight $\left(\bar{M}_{n}=1000-4000\right)$. The rate constants of propagation and termination $\left(k_{\mathrm{p}}\right.$ and $k_{\mathrm{t}}$ ) were determined based on quantification of propagating radicals from the $\alpha$-ethylacrylates: $k_{\mathrm{p}}=8.6$ and $k_{\mathrm{t}} 2.1 \times 10^{7} \mathrm{~L} \mathrm{~mol}^{-1} \mathrm{~s}$ for MEA, and $k_{\mathrm{p}}=1.6$ and $k_{\mathrm{t}}=1.8 \times 10^{6} \mathrm{~L} \mathrm{~mol}^{-1} \mathrm{~s}$ for CHEA. The steric hindrance of the ethyl group was found to bring about slower propagation and slightly slower termination rates of MEA in comparison with methyl methacrylate (MMA). The detailed structural analysis of the end group in the polymer indicates that replacement of the $\alpha$-methyl group of MMA with the ethyl group of MEA results in termination involving mainly combination $(76 \%)$. The steric hindrance seems to affect the termination mode.

KEY WORDS Radical Polymerization / $\alpha$-Ethylacrylate / $\alpha$-Substituted Acrylic Ester / Propagation Rate Constant / Termination Rate Constant / Electron Spin Resonance Spectroscopy /
\end{abstract}

Among 1,1-disubstituted ethylenic monomers, a variety of $\alpha$-substituted acrylates except for the acrylates bearing a large alkyl group and functioning as a chain transfer agent through the addition-fragmentation are polymerizable. ${ }^{1}$ Recent studies of radical polymerization of the $\alpha$-(substituted methyl)acrylates have drawn much attention because slight changes in the structure of the $\alpha$-substituent greatly affect the polymerizability. The $\alpha$-(substituted methyl)acrylates bearing alkoxymethyl, ${ }^{2}$ acyloxymethyl, ${ }^{3}$ fluoromethyl, ${ }^{4}$ and carboalkoxymethyl groups 5 as the $\alpha$-substituent readily polymerize to high molecular weight in spite of the presence of the bulky substituent. The absolute rate constants of propagation and termination $\left(k_{\mathrm{p}}\right.$ and $k_{\mathrm{t}}$ ) for the alkoxymethyl, acyloxymethyl and carboalkoxymethyl derivatives have been determined based on quantification of the respective propagating radicals by the ESR method, ${ }^{2,3,5}$ and it has been rationalized that the balance between the slow propagation and termination rates allows polymer formation from the $\alpha$-(substituted methyl)acrylates. Therefore, it is convinced that the steric hindrance of the $\alpha$-substituent provides steric hindrance-assisted polymerization of $\alpha$-(substituted methyl)acrylates. ${ }^{1}$

In the course of a further search for polymerizable $\alpha$-substituted acrylates, we found that $\alpha$-[2,2-bis(carboalkoxy)ethyl]acrylate readily polymerizes and copolymerizes through a radical chain mechanism involving extremely slow propagation and termination. ${ }^{6}$ Among the related acrylic monomers, methyl $\alpha$-(2-carbomethoxyethyl)acrylate has also been confirmed as a polymerizable monomer. ${ }^{7,8}$ We deduced that slight structural change in $\alpha$-substituent seriously affects the polymerizability of the $\alpha$-substituted acrylate almost irrespective the size of the substituent. However, methyl $\alpha-[2,2,2-$ tris(carboalkoxy)ethyl]acrylates do not polymerize because of the steric congestion against propagation; whereas, the primary propagating radical consisting of an initiator fragment and one monomeric unit produced by addition of the primary radical has been detected by ESR spectroscopy. ${ }^{9}$ Consequently, the size of the 2,2,2-tricarboalkoxyethyl group is indicated to be beyond the limit allowing sufficiently fast propagation to high molecular weight.<smiles>C=C(CCC(C(=O)O)C(=O)O)C(=O)O</smiles>

$\alpha$-[2,2-bis(carboalkoxy)ethyl]acrylate<smiles>C=C(CC(C(=O)O)(C(=O)O)C(=O)O)C(=O)O</smiles>

$\alpha-[2,2,2$-tris(carboalkoxy)ethyl]acrylate

On the other hand, methyl $\alpha$-ethylacrylate (MEA) polymerizes slowly to low molecular weight because of the steric hindrance of the $\alpha$-ethyl group. ${ }^{10,11} \alpha$-Ethylacrylic ester has been emphasized as a non-polymerizable compound in contrast to highly polymerizable methyl methacrylate (MMA). Although much larger $\alpha$ substituents allows high polymer, a difference in the size of the alkyl groups is considered to be a main factor of the different polymerization behavior. The low polymerizability of MEA is not consistent with the aspects of the steric hindrance-assisted polymerization of the $\alpha$-(substituted methyl)acrylate. The absolute values of $k_{\mathrm{p}}$ and $k_{\mathrm{t}}$ are required for further discussion on the polymerizabilities of MMA and MEA relating to the scope of steric hindrance-assisted polymerization.

A significant decrease in $k_{\mathrm{t}}$ of methacrylic ester by introduction of a bulky and rigid cycloalkyl ester group 
has been reported, ${ }^{12}$ and a bulky ester substituent of $\alpha$-ethylacrylates was expected to decrease the termination rate. If the $\alpha$-ethylacrylate bearing the bulky ester alkyl group has similar $k_{\mathrm{p}}$ and smaller $k_{\mathrm{t}}$ values than those of MEA, the $\alpha$-ethylacrylate could polymerize to high molecular weight as a result of a favorable balance between the slow propagation and termination rates. The present work deals with the radical polymerizations of MEA and cyclohexyl $\alpha$-ethylacrylate (CHEA) to shed light on the steric effect of the $\alpha$-ethyl group.<smiles>C=C(CC)C(=O)OC</smiles>

MEA

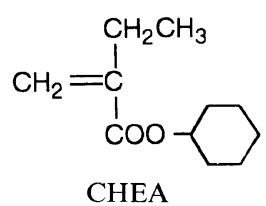

CHEA

\section{EXPERIMENTAL}

\section{Materials}

MEA was synthesized according to the method described in the literature. ${ }^{10,11}$ CHEA was prepared by the reaction of $\alpha$-ethylacryloyl chloride and cyclohexanol. $\alpha$ Ethylacryloyl chloride was obtained by the reaction of $\alpha$ ethylacrylic acid ${ }^{13}$ ( $50 \mathrm{~g}$; $\left.0.50 \mathrm{~mol}\right)$ with thionyl chloride $(55 \mathrm{ml})$ in the presence of a few drops of pyridine. Distilled $\alpha$-ethylacryloyl chloride $(42 \mathrm{~g} ; 0.35 \mathrm{~mol})$ was added to the benzene solution of cyclohexanol $(44 \mathrm{~g} ; 0.44 \mathrm{~mol})$ and triethylamine $(44 \mathrm{~g} ; 0.43 \mathrm{~mol})$ at $10^{\circ} \mathrm{C}$ or below. After the reaction mixture was refluxed for an hour, it was washed three times with water. The organic layer was dried over sodium sulfate and filtered. After evaporation of benzene, the residue was distilled under reduced pressure. CHEA was obtained in the amount of $44 \mathrm{~g}(48 \%$ from $\alpha$ ethylacrylic acid). Pure CHEA was obtained by distillation repeatedly (bp $55^{\circ} \mathrm{C} / 0.5 \mathrm{mmHg}$ ). The structures of MEA and CHEA were verified by ${ }^{1} \mathrm{H}$ and ${ }^{13} \mathrm{C}$ NMR spectroscopy.

MEA; ${ }^{1} \mathrm{H}$ NMR $\left(\mathrm{CDCl}_{3}\right): \delta=1.08(\mathrm{t}, J=7.3 \mathrm{~Hz}, 3 \mathrm{H}$, $\left.\mathrm{C}=\mathrm{CCH}_{2} \mathrm{CH}_{3}\right), 2.33\left(\mathrm{q}, J=7.3 \mathrm{~Hz}, 2 \mathrm{H}, \mathrm{C}=\mathrm{CC}_{2} \mathrm{CH}_{3}\right)$, $3.75\left(\mathrm{~s}, 3 \mathrm{H}, \mathrm{COOCH}_{3}\right), 5.53(\mathrm{~s}, 1 \mathrm{H}, \mathrm{CH}=\mathrm{C}), 6.13(\mathrm{~s}$, $1 \mathrm{H}, \mathrm{CH}=\mathrm{C}) .{ }^{13} \mathrm{C} \mathrm{NMR}\left(\mathrm{CDCl}_{3}\right): \delta=12.6\left(\mathrm{CH}_{2} \underline{\mathrm{CH}_{3}}\right)$, $24.8\left(\mathrm{CH}_{2} \mathrm{CH}_{3}\right), 51.6\left(\mathrm{OCH}_{3}\right), 123.3\left(\mathrm{CH}_{2}=\mathrm{C}\right), 142.2$ $\left(\mathrm{CH}_{2}=\mathrm{C}\right), 167.7(\mathrm{C}=\mathrm{O})$. CHEA; ${ }^{1} \mathrm{H} \mathrm{NMR}\left(\mathrm{CDCl}_{3}\right)$ : $\delta=1.08\left(\mathrm{t}, J=7.3 \mathrm{~Hz}, 3 \mathrm{H}, \mathrm{C}=\mathrm{CCH}_{2} \mathrm{CH}_{3}\right), \quad 1.2-2.0$ (m, 10H, cyclohexyl group), $2.33(\mathrm{q}, J=7.3 \mathrm{~Hz}, 2 \mathrm{H}$, $\left.\mathrm{C}=\mathrm{CCH}_{2} \mathrm{CH}_{3}\right), 4.86(\mathrm{~m}, 1 \mathrm{H}, \mathrm{COOCH}), 5.49(\mathrm{~s}, 1 \mathrm{H}$, $\mathrm{CH}=\mathrm{C}), 6.12(\mathrm{~s}, 1 \mathrm{H}, \mathrm{CH}=\mathrm{C}) .{ }^{13} \mathrm{C} \mathrm{NMR}\left(\mathrm{CDCl}_{3}\right)$ : $\delta=12.6\left(\mathrm{CH}_{2} \mathrm{CH}_{3}\right), 23.5\left(3-\mathrm{CH}_{2}\right), 24.8\left(\mathrm{CH}_{2} \mathrm{CH}_{3}\right), 25.4$ $\left(4-\mathrm{CH}_{2}\right), 31.4\left(2-\mathrm{CH}_{2}\right), 72.4(\mathrm{OCH}), 122.8\left(\mathrm{CH}_{2}=\mathrm{C}\right)$, $142.9\left(\mathrm{CH}_{2}=\underline{\mathrm{C}}\right), 166.6(\mathrm{C}=\mathrm{O})$.

Ethyl methacrylate (EMA) was commercially available and distilled under reduced pressure. Commercial dimethyl 2,2'-azobis(isobutyrate) (MAIB) and 2,2'azobis(isobutyronitrile) (AIBN) as initiators were used after recrystallization. 1,3,5-Triphenylverdazyl (TPV) was synthesized as described in the literature ${ }^{14}$ and recrystallized from methanol.

\section{Polymerization Procedure}

All the polymerizations and copolymerizations were carried out in glass tubes sealed under vacuum. After polymerization for a prescribed time, a $\mathrm{CDCl}_{3}$ solution of the polymerization mixture was directly subjected by ${ }^{1} \mathrm{H}$ NMR measurement to determine the amount of unreacted monomer. Furthermore, the polymers of MEA and CHEA were isolated by pouring the contents of the tube into a large amount of aqueous methanol. The copolymers of MEA with EMA were precipitated by $n$-hexane. The overall rate of copolymerization was determined from the weight of the polymeric product and the copolymer composition. The compositions of the copolymer were calculated from the ratio of intensities of the resonances at 3.3-3.8 and 3.9-4.2 ppm due to $\mathrm{COOCH}_{3}$ and $\mathrm{COOC} \underline{H}_{2} \mathrm{CH}_{3}$ of the respective monomeric units. Monomer reactivity ratios $\left(r_{1}\right.$ and $\left.r_{2}\right)$ were evaluated by a non-linear least-squares procedure. ${ }^{15}$

\section{Spectroscopy}

${ }^{1} \mathrm{H}$ and ${ }^{13} \mathrm{C}$ NMR spectra were recorded on a JEOL JNM-A400 spectrometer at 400 and $100 \mathrm{MHz}$, respectively. Deuteriochloroform and tetramethylsilane were used as the solvent and internal standard, respectively. ESR spectra of the propagating radicals were taken by a Bruker ESP-300 spectrometer at X band $(9.50 \mathrm{GHz})$ with $100 \mathrm{kHz}$ field modulation at a microwave power of $10.0 \mathrm{~mW}$ to avoid saturation. The spectra were recorded at a modulation amplitude of $8 \mathrm{G}$ after an accumulation of ten scans for MEA and four scans for CHEA over a magnetic field of $120 \mathrm{G}$ in width centered at $3395 \mathrm{G}$ divided into 1024 points, and the conversion time and time constant of each point were 40.96 and $655.36 \mathrm{~ms}$, respectively. Having been sealed under vacuum, a $3 \mathrm{~mm}$ o.d. quartz tube containing the monomer and initiator was maintained at polymerization temperature in the cavity. The ESR spectral intensity was obtained by double integration. The concentration of the propagating radicals was calibrated by the signal intensity of TPV dissolved in the monomer.

\section{Measurements}

Number- and weight-average molecular weights $\left(\bar{M}_{n}\right.$ and $\bar{M}_{w}$ ) of the resultant polymers and copolymers were determined with a Tosoh 8000 series high-performance liquid chromatograph equipped with columns for gel-permeation chromatography (GPC) packed with TSK Gel G7000HHR, G6000HHR, 4000HHR, and G2000HHR connected in this order at $38^{\circ} \mathrm{C}$. Tetrahydrofuran was used as eluent and standard poly(St) was employed for calibration. $\bar{M}_{n}$ was also measured by a Knauer vapour pressure osmometer (VPO) at $40^{\circ} \mathrm{C}$ and toluene was used as solvent.

\section{RESULTS AND DISCUSSION}

\section{Polymerization}

In the recent study of radical polymerization of MEA in bulk, the poly(MEA) of $\bar{M}_{n}=2100$ was obtained at $12 \%$ conversion after $25 \mathrm{~h}$ with $\operatorname{AIBN}\left(0.1669 \mathrm{~mol} \mathrm{~L}^{-1}\right)$ at $61{ }^{\circ} \mathrm{C} .{ }^{11}$ The polymer precipitated in aqueous methanol $(50 \mathrm{vol} / \mathrm{vol})$ exhibited a smaller polydispersity $\left(\bar{M}_{w} / \bar{M}_{n}=\right.$ 1.39) than that for the conventional radical polymerization $\left(\bar{M}_{w} / \bar{M}_{n}=1.5-2.0\right) .{ }^{16}$ Because this finding suggests that the oligomeric product is soluble in the precipitant, the polymerization rate estimated by this method seemed to be lower than the actual polymerization rate. Further- 
more, the conversion of the monomer determined was evaluated without consideration of an initiator fragment at the polymer chain end. The exact conversion may be obtained by quantification of unchanged monomer in the polymerization mixture by spectroscopy or chromatography.

Radical polymerization of MEA was carried out using MAIB as initiator in bulk at $60^{\circ} \mathrm{C}$. The polymerization was expected to be slow, and a large amount of MAIB $\left(0.10 \mathrm{~mol} \mathrm{~L}^{-1}\right)$ corresponding to $1.25 \mathrm{~mol} \%$ of MEA was dissolved in the monomer. Figure 1 (top) depicts the conversion-time relationship, where the conversion was measured by ${ }^{1} \mathrm{H}$ NMR spectroscopy. Intensity of the resonance assigned to the olefinic protons of unchanged MEA (5.53 and $6.13 \mathrm{ppm}$ ) was compared with that of the methoxy protons of the monomeric and polymeric MEA at 3.5-4.0 ppm.

Because the polymerization was carried out for a long period, a decrease in initiator concentration should be considered. The overall rate of polymerization $\left(R_{\mathrm{p}}\right)$ is expressed by eq 1 according to the standard kinetics of radical polymerization at the steady-state.

$$
R_{\mathrm{p}}=-\mathrm{d}[\mathrm{M}] / \mathrm{d} t=k[\mathrm{M}][\mathrm{I}]^{0.5}
$$

where $[\mathrm{M}]$ and $[\mathrm{I}]$ are the concentrations of monomer and initiator, respectively. Because [I] decreases with time at polymerization temperature, $[\mathrm{I}]$ is represented by eq 2 using initial $[\mathrm{I}]\left([\mathrm{I}]_{0}\right)$.
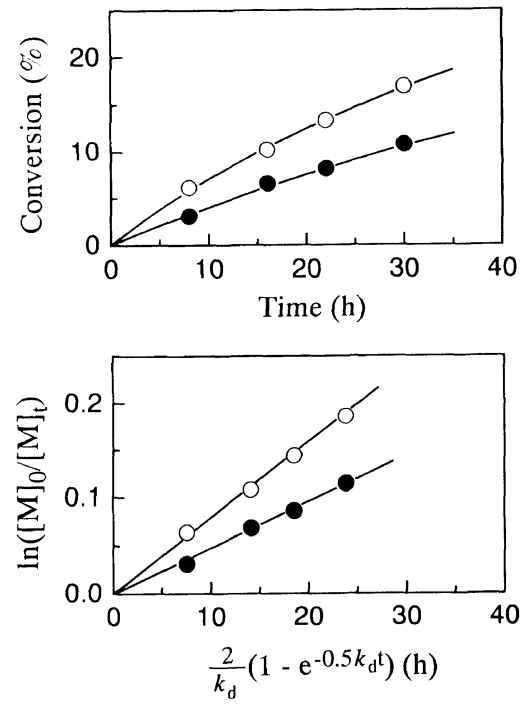

Figure 1. Time-conversion relationships (top) and the first-order kinetic plots using eq 3 (bottom) for the bulk polymerization of MEA (O) and CHEA (O) at $60^{\circ} \mathrm{C}:[\mathrm{MAIB}]=0.10 \mathrm{~mol} \mathrm{~L}^{-1}$.

$$
[\mathrm{I}]=[\mathrm{I}]_{0} \exp \left(-k_{\mathrm{d}} t\right)
$$

where $k_{\mathrm{d}}$ denotes the unimolecular decomposition rate constant of the initiator. By substitution of eq 2 in eq 1 , the integrated form of eq 1 may be given by eq 3 .

$$
\begin{aligned}
\ln \left([\mathrm{M}]_{0} /[\mathrm{M}]_{t}\right) & =\left(k[\mathrm{I}]_{0}{ }^{0.5}\right)\left(2 / k_{\mathrm{d}}\right)\left\{1-\exp \left(-0.5 k_{\mathrm{d}} t\right)\right\} \\
& =\left(R_{\mathrm{p}, 0} /[\mathrm{M}]_{0}\right)\left(2 / k_{\mathrm{d}}\right)\left\{1-\exp \left(-0.5 k_{\mathrm{d}} t\right)\right\}
\end{aligned}
$$

where $[\mathrm{M}]_{0}$ and $[\mathrm{M}]_{t}$ are designated to $[\mathrm{M}]$ at the initial and after $t$ seconds, respectively.

Initial $R_{\mathrm{p}}\left(R_{\mathrm{p}, 0}\right)$ was estimated from the slope of the linear relationship in Figure 1 (bottom) of which the slope means $R_{\mathrm{p}, 0} /[\mathrm{M}]_{0}$ according to eq $3^{8}: R_{\mathrm{p}}=1.7 \times$ $10^{-5} \mathrm{~mol} \mathrm{~L}^{-1} \mathrm{~s}$.

Table I shows the results of bulk polymerization of MEA together with those of methyl $\alpha$-(2-carbomethoxyethyl)acrylate (MMEA), methyl $\alpha$-[2,2-bis(carbomethoxy)-ethyl] acrylate [M(DM)EA], and methyl $\alpha-[2,2,2-$ tris(carboethoxy)ethyl]acrylate [M(TE)EA]. MEA polymerizes slowly to low molecular weight as previously reported by Penelle et al. ${ }^{11}$ However, MMEA and M(DM)EA yielded higher molecular weight polymers at the much faster rates than MEA. These monomers bearing large $\alpha$-substituents yield the polymers through the steric hindrance-assisted polymerization. ${ }^{1}$

Bulk polymerization of $\mathrm{CHEA}$ at $60^{\circ} \mathrm{C}$ was run in a method similar to MEA polymerization; Figure 1 shows the time-conversion relationship and the first-order plot. Because the slope of the linear relationship obtained from the first-order plot indicates $R_{\mathrm{p}, 0} /[\mathrm{M}]_{0}, R_{\mathrm{p}, 0}$ was estimated to be $6.6 \times 10^{-6} \mathrm{~mol} \mathrm{~L}^{-1} \mathrm{~s}$. The polymer from CHEA was obtained at a slower rate than MEA by a factor of 1.7 under comparable conditions.

Methacrylic esters bearing bulky ester alkyl substituents such as cyclohexyl, fused-ring, adamantyl, and long alkyl groups show $k_{\mathrm{p}}$ values similar to that of MMA. ${ }^{12}$ However, it has been revealed that $k_{\mathrm{t}}$ decreases with an increase in bulkiness of the substituent. Consequently, those monomers with smaller $k_{\mathrm{t}}$ values polymerize rapidly to high molecular weight. In contrast to the expectation, CHEA polymerized slower than MEA. These findings indicate that the steric congestion of the $\alpha$-and ester alkyl substituents of the $\alpha$-ethylacrylate is greater than that of methacrylate and that further increase in size of the $\alpha$-alkyl substituent hinders

\begin{tabular}{|c|c|c|c|c|c|c|}
\hline \multirow{2}{*}{ Monomer } & \multirow{2}{*}{$\frac{[\mathrm{M}]_{0}}{\mathrm{~mol} \mathrm{~L}^{-1}}$} & \multirow{2}{*}{$\frac{[\mathrm{I}]_{0}^{\mathrm{a}}}{\mathrm{mol} \mathrm{L}^{-1}}$} & \multirow{2}{*}{$\frac{R_{\mathrm{p}} /[\mathrm{M}]_{0}[\mathrm{I}]_{0}^{0.5} \times 10^{6}}{\mathrm{~L}^{0.5} \mathrm{~mol}^{-0.5} \mathrm{~s}}$} & \multirow{2}{*}{$\begin{array}{c}\bar{M}_{n} \\
(\mathrm{GPC})\end{array}$} & \multirow{2}{*}{$\begin{array}{c}\bar{M}_{w} / \bar{M}_{n} \\
(\mathrm{GPC})\end{array}$} & \multirow{2}{*}{ Ref } \\
\hline & & & & & & \\
\hline MEA & 8.0 & 0.10 & 6.8 & 1900 & 1.71 & This work \\
\hline CHEA & 5.1 & 0.10 & 4.1 & 1500 & 1.74 & This work \\
\hline MMEA & 6.2 & 0.050 & 79 & 38000 & 1.90 & 8 \\
\hline $\mathrm{M}(\mathrm{DM}) \mathrm{EA}$ & 5.0 & 0.050 & 43 & 19400 & 1.62 & 6 \\
\hline M(TE)EA & 3.0 & 0.050 & 0 & - & - & 9 \\
\hline
\end{tabular}
propagation and termination simultaneously in similar manner.

Table I. Results of bulk polymerization of $\alpha$-substituted acrylates at $60^{\circ} \mathrm{C}$

a MAIB as an initiator. 


\section{Absolute Rate Constants}

According to standard kinetics of radical polymerization, $k_{\mathrm{p}}$ is given by a simple equation ${ }^{16}$ :

$$
k_{\mathrm{p}}=R_{\mathrm{p}} /\left(\left[\mathrm{M}^{\cdot}\right][\mathrm{M}]\right)
$$

$R_{\mathrm{p}}$ 's for MEA and CHEA were experimentally determined, and the concentration of the propagating radical $\left(\left[\mathrm{M}^{\circ}\right]\right)$ may be obtained by ESR spectroscopy for evaluation of $k_{\mathrm{p}} . R_{\mathrm{p}}$ corresponds to $R_{\mathrm{p}, 0}$ in eq 3 at the initial stage of polymerization. ESR measurement was carried out under conditions comparable with those of the polymerization. Care was taken to avoid distortion of the line shape and saturation. The ESR spectra were measured within an hour $(<1 \%$ conversion $)$, and change in the sensitivity of the cavity with conversion was neglected. The propagating radicals from MEA and CHEA were observed as 5-line spectra as shown in Figure 2, and $\left[\mathrm{M}^{\circ}\right]$ remained constant during the ESR measurement $(<1 \mathrm{~h})$. The constant $\left[\mathrm{M}^{\circ}\right]$ is consistent with the fact that a decrease in MAIB concentration is estimated to be $1.6 \%$ after heating for $1 \mathrm{~h}$ at $60^{\circ} \mathrm{C}$.

By substitution of $R_{\mathrm{p}},\left[\mathrm{M}^{\circ}\right]$, and [M] in eq $4, k_{\mathrm{p}}$ 's were evaluated to be 8.6 and $1.6 \mathrm{~L} \mathrm{~mol}^{-1} \mathrm{~s}$ for MEA and CHEA, respectively. Table II shows $\left[\mathrm{M}^{\circ}\right]$ and $k_{\mathrm{p}}$ for MEA and CHEA together with those for MMEA, $\mathrm{M}(\mathrm{DM}) \mathrm{EA}$, and M(TE)EA. The apparent $k_{\mathrm{p}}$ value of $\mathrm{M}(\mathrm{TE}) \mathrm{EA}$ was estimated based on $\left[\mathrm{M}^{\circ}\right]$ and $k_{\mathrm{t}}$ of the primary propagating radical of $\mathrm{M}(\mathrm{TE}) \mathrm{EA}$ which does not propagate further, and the $k_{\mathrm{p}}$ value should be less
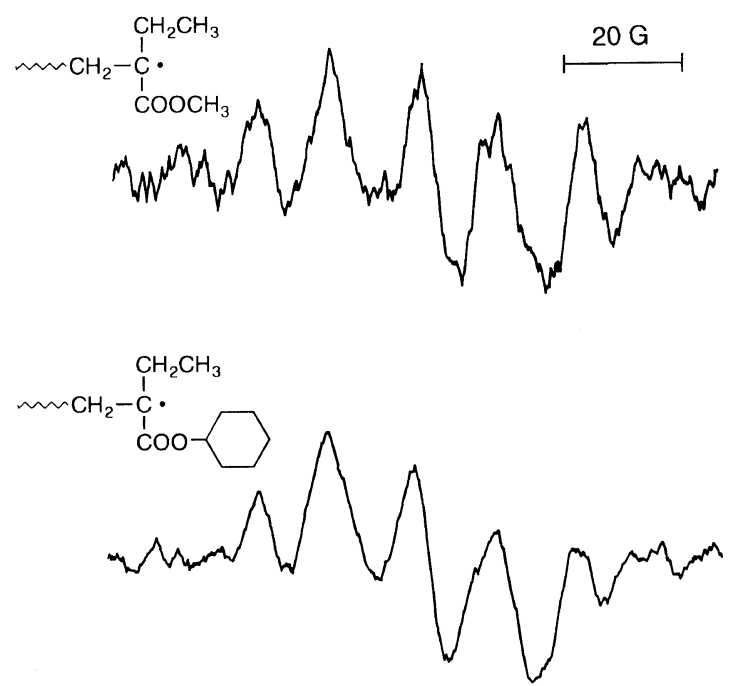

Figure 2. ESR spectra observed during the bulk polymerizations of MEA (top) and CHEA (bottom) at $60^{\circ} \mathrm{C}:[\mathrm{MAIB}]=0.10 \mathrm{~mol} \mathrm{~L}^{-1}$. than $0.003 \mathrm{~L} \mathrm{~mol}^{-1} \mathrm{~s}$. Slightly smaller $k_{\mathrm{p}}$ values of MEA and $\mathrm{M}(\mathrm{DM}) \mathrm{EA}$ than that of MMEA may be ascribed by a relatively low ceiling temperature $\left(T_{\mathrm{c}}\right)$. If these polymerizations are affected by $T_{\mathrm{c}}$, the $k_{\mathrm{p}}$ values obtained correspond to the apparent values $\left(k_{\mathrm{p}}{ }^{\prime}\right)$ defined by eq $5^{16}$ :

$$
k_{\mathrm{p}}{ }^{\prime}=k_{\mathrm{p}}-k_{\mathrm{dp}} /[\mathrm{M}]
$$

where $k_{\mathrm{dp}}$ denotes the rate constant of depropagation. Hypothetical propagation of M(TE)EA seems to be too slow under the influence of $T_{\mathrm{c}}$. As previously indicated, $T_{\mathrm{c}}$ 's for MEA and M(DM)EA in bulk are $82^{11}$ and $90^{\circ} \mathrm{C}$, ${ }^{6}$ respectively, and $T_{\mathrm{c}}$ for MMEA was estimated to be higher than $100^{\circ} \mathrm{C} .^{8}$ Higher molecular weight polymers have been obtained from these monomers; whereas, all these $T_{\mathrm{c}}$ 's are lower than that for MMA. The polymerizability of $\alpha$-substituted acrylate appears to be affected by the balance of the rates of the elementary reactions and $T_{\mathrm{c}}$.

If the primary radical termination is negligible, the $k_{\mathrm{t}}$ value can be evaluated from eq 6 at the steady-state ${ }^{16}$ :

$$
\mathrm{d}\left[\mathrm{M}^{\bullet}\right] / \mathrm{d} t=R_{\mathrm{i}}-k_{\mathrm{t}}\left[\mathrm{M}^{\cdot}\right]^{2}=0
$$

High concentration of initiator and slow addition of the primary radical to the monomer tend to result in the primary radical termination. $R_{\mathbf{i}}$ was determined by a scavenger method using TPV as a stable radical based on the assumption that the primary radical emerging out of the cage is quantitatively trapped: $R_{\mathrm{i}}=1.3 \times 10^{-6}$ and $1.1 \times 10^{-6} \mathrm{~mol} \mathrm{~L}^{-1} \mathrm{~s}$ for MEA and CHEA, respectively. A slower $R_{\mathrm{i}}$ for CHEA may arise from the higher viscosity of CHEA than MEA relating to lower initiating efficiency $(f)$ for CHEA. $\left[\mathrm{M}^{\circ}\right]$ remained constant during the ESR measurement as already mentioned, and we confirmed establishment of the steady-state. The $k_{\mathrm{t}}$ values were estimated from eq 6 using $R_{\mathrm{i}}$ and $\left[\mathrm{M}^{\bullet}\right]: k_{\mathrm{t}}=2.1 \times 10^{7}$ and $1.8 \times 10^{6} \mathrm{~L} \mathrm{~mol}^{-1} \mathrm{~s}$ for MEA and CHEA, respectively.

Among the $k_{\mathrm{t}}$ values of $\alpha$-substituted acrylates at $60^{\circ} \mathrm{C}$ summarized in Table II, the $k_{\mathrm{t}}$ of MEA $\left(k_{\mathrm{t}}=2.1 \times 10^{7}\right.$ $\left.\mathrm{L} \mathrm{mol}^{-1} \mathrm{~s}\right)$ is smaller than that of MMA $\left(k_{\mathrm{t}}=4.2 \times 10^{7}\right.$ $\left.\mathrm{L} \mathrm{mol}^{-1} \mathrm{~s}\right)^{17}$ by a factor of two, and MMEA, M(DM)EA, and $\mathrm{M}(\mathrm{TE}) \mathrm{EA}$ have $k_{\mathrm{t}}$ values much smaller than that of MEA. Comparison of the series of the $k_{\mathrm{t}}$ values shows a decrease in the $k_{\mathrm{t}}$ value with an increase in the bulkiness of the $\alpha$-substituent. It was concluded that the low polymerizability of MEA results in the combination of slower propagation than that of MMA and slightly slower termination. Therefore, the $\alpha$-ethylacrylate yields

\begin{tabular}{|c|c|c|c|c|c|}
\hline \multirow{2}{*}{ Monomer } & {$\left[\mathrm{M}^{\cdot}\right] \times 10^{7}$} & $k_{\mathrm{p}}$ & $k_{\mathrm{t}} \times 10^{-6}$ & $k_{\mathrm{p}} / k_{\mathrm{t}}^{0.5} \times 10^{3}$ & \multirow{2}{*}{ Ref } \\
\hline & $\mathrm{mol} \mathrm{L}^{-1}$ & $\mathrm{~L} \mathrm{~mol}^{-1} \mathrm{~s}$ & $\mathrm{~L} \mathrm{~mol}^{-1} \mathrm{~s}$ & $\mathrm{~L}^{0.5} \mathrm{~mol}^{-0.5} \mathrm{~s}^{0.5}$ & \\
\hline MEA & 2.5 & 8.6 & 21 & 1.9 & This work \\
\hline CHEA & 7.8 & 1.6 & 1.8 & 1.2 & This work \\
\hline MMEA & 9.5 & 19 & 0.51 & 27 & 8 \\
\hline $\mathrm{M}(\mathrm{DM}) \mathrm{EA}$ & 24 & 4.0 & 0.038 & 20 & 6 \\
\hline $\mathrm{M}(\mathrm{TE}) \mathrm{EA}^{\mathrm{b}}$ & 71 & $<0.003$ & 0.0013 & $\sim 0$ & 9 \\
\hline $\mathrm{MMA}^{\mathrm{c}}$ & 1.5 & 510 & 42 & 79 & 16 \\
\hline
\end{tabular}
the low molecular weight polymer which is conveniently

Table II. Kinetic parameters for bulk polymerization of $\alpha$-substituted acrylates at $60^{\circ} \mathrm{C}^{\mathrm{a}}$

${ }^{a}$ Polymerized under the conditions for the respective monomers in Table I. ${ }^{b}$ Attempted photopolymerization initiated with $2,2^{\prime}$-azobis(2,4,4trimethylpentane) as a photosensitizer at $60^{\circ} \mathrm{C}$. ${ }^{c}$ Polymerization initiated with AIBN in bulk: [AIBN] $=0.10 \mathrm{~mol} \mathrm{~L} \mathrm{~L}^{-1}$. 


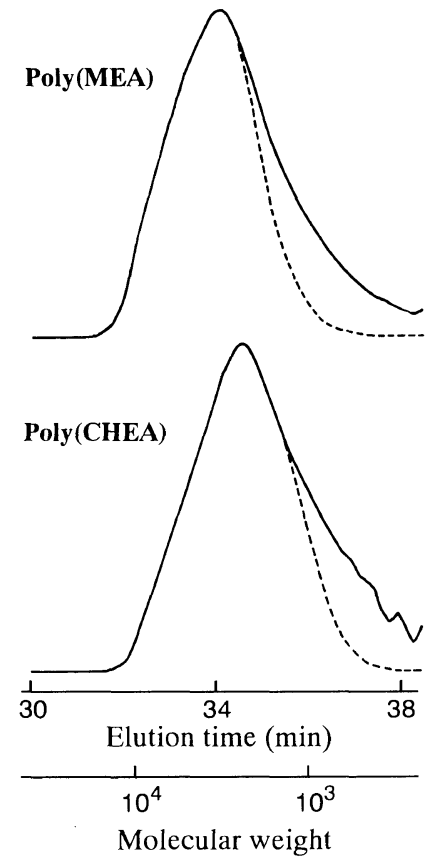

Figure 3. GPC elution curves of the polymerization mixture $(-)$ and polymer isolated (---).

used for structural analysis.

\section{Termination Mechanism}

GPC measurement of the polymerization mixture of MEA and CHEA after polymerization for $30 \mathrm{~h}$ exhibited formation of polymers of $\bar{M}_{n}=1900$ and 1500 , respectively. The colorless powdery polymers were isolated by reprecipitation using aqueous methanol. Figure 3 shows the GPC elution curves of the polymerization mixtures and the poly(MEA) and poly(CHEA) isolated. It was found that low molecular weight polymer was lost as the soluble fraction in aqueous methanol.

Disappearance of the carbon-carbon double bonds of MEA and CHEA by polymerization was confirmed by

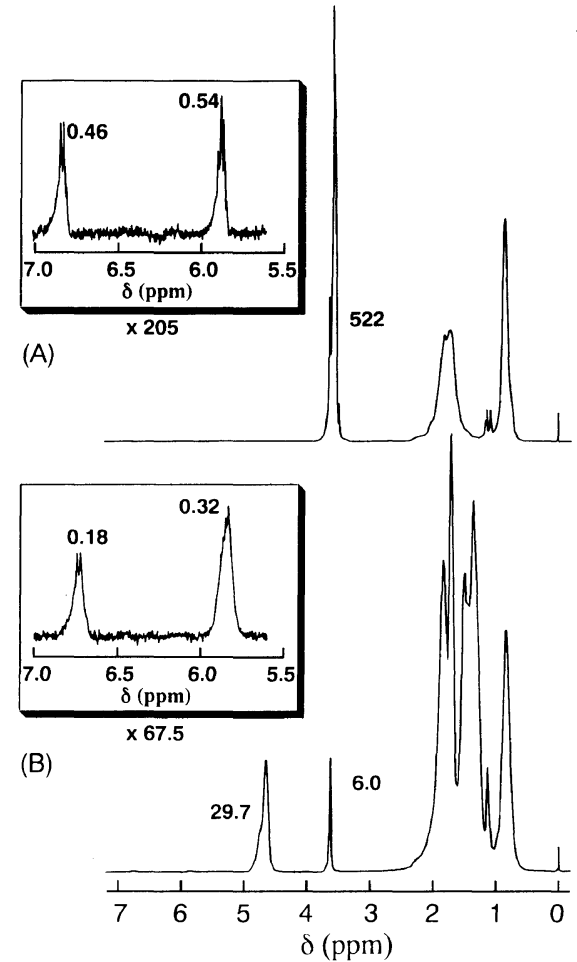

Figure 4. ${ }^{1} \mathrm{H}$ NMR spectra of poly(MEA) (A) and poly(CHEA) (B).

NMR spectroscopy. Methylene and methyl protons at $0.5-2.5 \mathrm{ppm}$ and methoxy protons at $3.4-3.8 \mathrm{ppm}$, which involve the resonances assigned to the initiator fragment, are observed in the ${ }^{1} \mathrm{H}$ NMR spectrum of the poly(MEA) as shown in Figure 4. Furthermore, the olefinic protons of the carbon-carbon double bond produced by disproportionation were detectable in the chemical shift range of $5-7 \mathrm{ppm}$ in the expanded ${ }^{1} \mathrm{H}$ NMR spectrum. Disproportionation of the poly(MEA) radical could form four types of unsaturated chain ends, $\mathbf{2}$ to $\mathbf{5}$, together with saturated chain end, $\mathbf{6}$.<smiles>[Y]CCC(CC)(CC)C(=O)O</smiles>

1<smiles>CCCC=CC(=O)OCC</smiles>

2<smiles>CC=C(CCC)CCC</smiles>

3<smiles>CC=C(CC)C(=O)O</smiles>

4<smiles>CC=C(CC)C(=O)O</smiles>

5<smiles>CCCCC(CC)C(=O)O</smiles><smiles>[R]=CCC1CCCCC1</smiles>

The resonances of the olefinic protons of $\mathbf{2}$ and $\mathbf{5}$ may appear at $5.88 \mathrm{ppm}$, and those of $\mathbf{3}$ and $\mathbf{4}$ at $6.85 \mathrm{ppm} .{ }^{18}$ The intensity ratio of the respective peaks at 5.88 and
$6.85 \mathrm{ppm}$ was estimated to be $54: 46$ for poly(MEA) and $64: 36$ for poly(CHEA) based on the expanded spectrum in Figure 4. Similar $\alpha$-substituted acrylic ester structures 
with 2 and 3 have been produced by dimerization of MEA using catalytic chain transfer with benzylbis(dimethylglyoximato)(pyridine)cobalt(III) as an equimolar mixture of compounds $\mathbf{7}$ and $\mathbf{8}$, of which the resonances assigned to the olefinic protons have also been observed at 5.95 and 6.92 ppm. $^{19}$<smiles>CC=C(CC(C)(CC)C(C)=O)C(=O)OC</smiles>

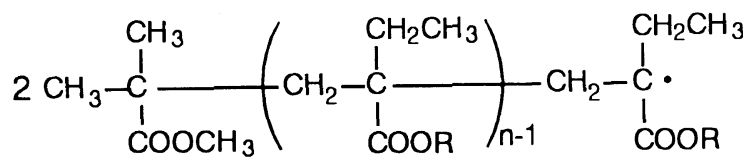<smiles>CC=C(CC(C)(CC)C(=O)O)C(=O)OC</smiles>

The resonances due to similar olefinic protons of the unsaturated end group bound to the polyester prepared from ethylene bis $(\alpha$-ethylacrylate) by catalytic chain transfer have been observed at 5.9 and 6.9 ppm. ${ }^{20}$

The quartet at 5.88 and $6.85 \mathrm{ppm}$ in the expanded ${ }^{1} \mathrm{H}$ NMR spectrum shown in Figure 4 suggests the presence of two types of end groups such as $\mathbf{2}$ and $\mathbf{3}$.

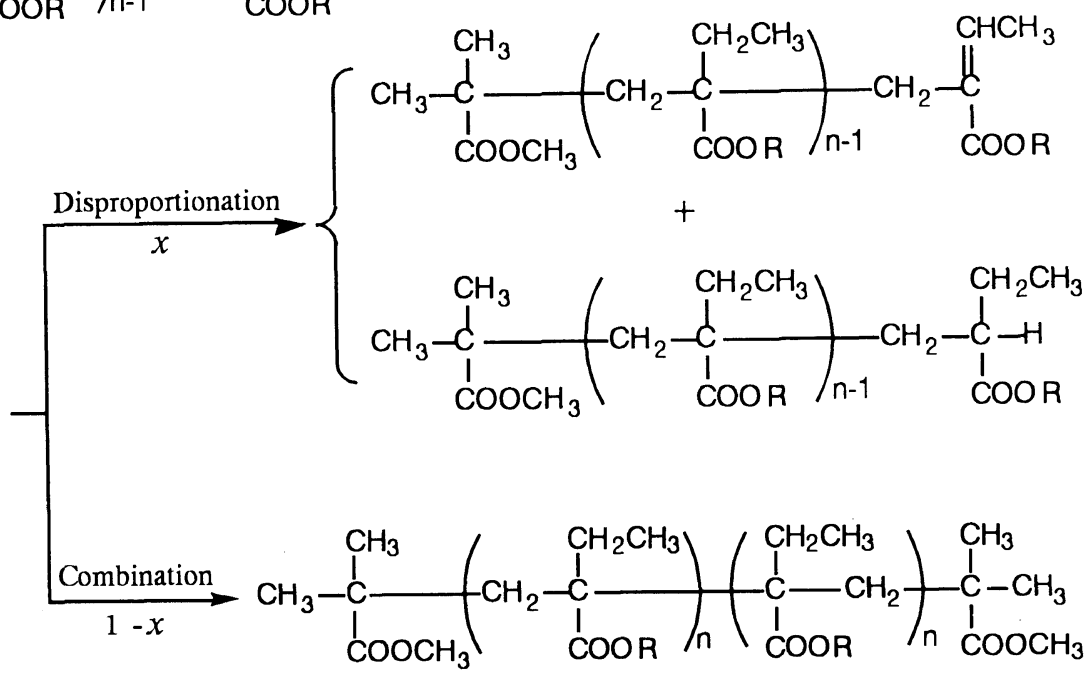

If the $\omega$-terminus of the polymer is formed only by bimolecular termination, the ratio of the respective peak intensities in the ${ }^{1} \mathrm{H}$ NMR spectrum of the polymer can be expressed as follows:

For poly(MEA):

$$
\left[\mathrm{OCH}_{3}\right]:[\mathrm{C}=\mathrm{CH}]=6(n+1): x=522: 1
$$

For poly(CHEA):

$$
\left[\mathrm{OCH}_{3}\right]:[\mathrm{OCH}]:[\mathrm{C}=\mathrm{CH}]=6: 2 n: x=6: 29.7: 0.50
$$

Table III summarizes the $\bar{M}_{n}$ of the polymers determined by different methods, and the $\bar{M}_{n}$ determined by GPC is smaller than that by VPO. Previously, it has been noted that the low molecular weight poly(MMA) shows a $10 \%$ lower $\bar{M}_{n}$ by GPC than VPO. ${ }^{21}$

If the proportion of disproportionation in bimolecular termination of radical 1 is $x$, the $\bar{M}_{n}$ of the resulting polymer may be expressed as follows:

$$
\bar{M}_{n}=2(101+n M) /(1+x)
$$

where $M$ is the molecular weight of the $\alpha$-ethylacrylate monomer and $n$ is chain length of propagating radical.

Combination of eq 9 based on $\bar{M}_{n}$ determined by VPO for poly(MEA) with eq 7 results in $x=0.24$ and $n=$ 19.8. Consequently, it is noted that $24 \%$ of the polymer radicals from MEA lose their activities by disproportionation. The values of $x$ and $n$ for poly(CHEA) were estimated to be 0.50 and 14.9 , respectively, from eq 8. Substitution of the numerical values in eq 9 gives $\bar{M}_{n}=3700$, which is larger than $\bar{M}_{n}$ determined by VPO, 2800 .

The unsaturated end group of poly(MMA) has been quantified by Hatada et al. using ${ }^{1} \mathrm{H}$ NMR spectroscopy: $72 \%$ of the polymer molecules is produced by dis-

Table III. Molecular weight of resultant polymers

\begin{tabular}{ccccc}
\hline \multirow{2}{*}{ Polymer } & \multicolumn{2}{c}{$\bar{M}_{n}(\mathrm{GPC})$} & \multicolumn{1}{c}{$\begin{array}{c}\bar{M}_{n}(\mathrm{VPO}) \\
\text { after precipitation }\end{array}$} & $\bar{M}_{n}(\mathrm{VPO}) / \bar{M}_{n}(\mathrm{GPC})$ \\
\cline { 2 - 4 } & Polymerization mixture & After precipitation & 3800 & 1.31 \\
Poly(MEA) & 1900 & 2900 & 2800 & 1.40 \\
Poly(CHEA) & 1500 & 2000 & \\
\hline
\end{tabular}


proportionation. $^{22}$ This means that $56 \%$ of the propagating radicals of MMA terminate by disproportionation. $^{23}$ Lower probabilities of disproportionation in MEA $(x=0.24)$ and CHEA $(x=0.50)$ polymerizations than in MMA polymerization $(x=0.56)$ seems to be influenced at least in part by the steric congestion of the $\alpha$-ethyl group. However, $x$ is determined by competition between disproportionation and combination and both reactions are subject to steric hindrance. The bulky cyclohexyl group of CHEA suppressed combination in the termination process in comparison with that for MEA polymerization. Consequently, the $x$ values for the ethylacrylates should be regarded as the result of the balance between slower disproportionation and combination.

\section{Kinetic Chain Length}

The kinetic chain length $(v)$, which corresponds to the $n$ value in eq 9 , is given by the ratio of the polymerization rate to the initiation rate or termination rate according to eq $10^{16}$ :

$$
v=R_{\mathrm{p}} / R_{\mathrm{i}}=R_{\mathrm{p}} / R_{\mathrm{t}}
$$

The values of $R_{\mathrm{p}}$ and $R_{\mathrm{i}}$ were determined to be $R_{\mathrm{p}}=1.7 \times 10^{-5} \mathrm{~mol} \mathrm{~L}^{-1} \mathrm{~s}$ and $R_{\mathrm{i}}=1.3 \times 10^{-6} \mathrm{~mol} \mathrm{~L}^{-1} \mathrm{~s}$ for the MEA polymerization, and the $v$ value was estimated to be 13.1 from eq 10 . If the $x$ value is 0.24 , $\bar{M}_{n}=2600$ at $n=v=13.1$ is obtained from eq 9 . The estimate from eq 9 is larger than $\bar{M}_{n}$ determined by the direct GPC measurement of the polymerization mixture $\left(\bar{M}_{n}=1900\right)$. Because the $\bar{M}_{n}$ (VPO) is larger than the $\bar{M}_{n}$ (GPC) by a factor of 1.31 as shown in Table III, the $\bar{M}_{n}$ of the polymer in the polymerization mixture may be calculated to be $1900 \times 1.31=2500$. Fair agreement of the $\bar{M}_{n}$ from the kinetic chain length with that of the polymer produced indicates that the bimolecular termination is predominant as the chain stopping process in MEA polymerization.

The $v$ value for the polymerization of CHEA is estimated to be 6.0 from eq 10. Substitution of $x=0.50$ and $n=v=6.0$ in eq 7 leads to $\bar{M}_{n}=1600$. The $\bar{M}_{n}$ of poly(CHEA) of the polymerization mixture may be calculated to be $1500 \times 1.40=2100$, of which the value is larger than that determined from the kinetic chain length. A difference in the $k_{\mathrm{p}}$ value for the first few steps of propagation has been suggested in the polymerizations of styrene (St) and methyl acrylate. ${ }^{24}$ The $k_{\mathrm{p}}$ value in the early stage of propagation is larger than that for propagation of the propagating radical. The $k_{\mathrm{p}}$ of CHEA may change with the chain length of the propagating radical with low molecular weight considering the short kinetic chain length, $v=6$.

It was concluded that bulk polymerization of the $\alpha$-ethylacrylates follows the standard kinetics of radical polymerization involving initiation, propagation, and termination, and the primary radical termination and chain transfer were ruled out from these polymerizations.

\section{Copolymerization}

Copolymerization of MEA $\left(\mathrm{M}_{2}\right)$ with EMA $\left(\mathrm{M}_{1}\right)$ was carried out using AIBN at $60^{\circ} \mathrm{C}$. Figure 5 shows the ${ }^{1} \mathrm{H}$ NMR spectrum of the copolymer obtained from an

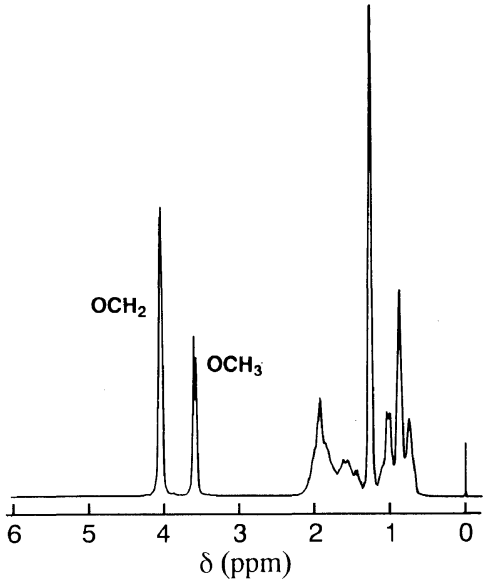

Figure 5. ${ }^{1} \mathrm{H}$ NMR spectrum of copolymer of MEA with EMA obtained at $60^{\circ} \mathrm{C}:[\mathrm{MEA}]=1.2 \mathrm{~mol} \mathrm{~L}^{-1},[\mathrm{EMA}]=1.2 \mathrm{~mol} \mathrm{~L}^{-1}$, and $[\mathrm{AIBN}]=5.0 \times 10^{-3} \mathrm{~mol} \mathrm{~L}^{-1}$.
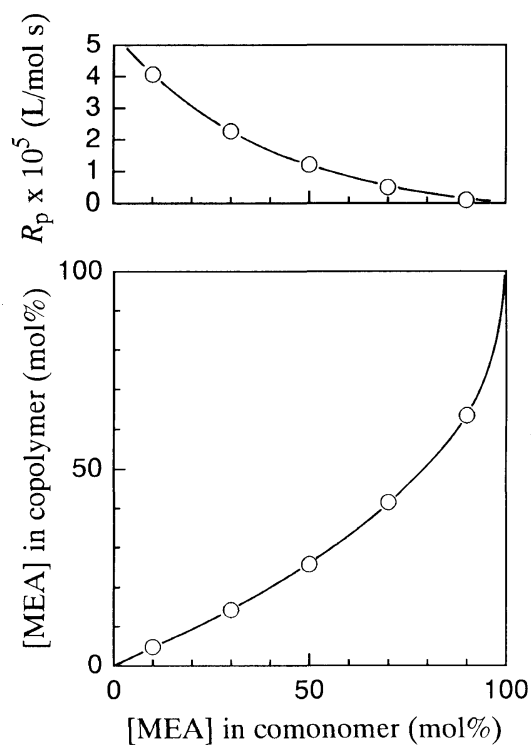

Figure 6. Comonomer-copolymer composition curve for copolymerization of $\operatorname{MEA}\left(\mathrm{M}_{2}\right)$ with $\operatorname{EMA}\left(\mathrm{M}_{1}\right)$ in benzene at $60^{\circ} \mathrm{C}$

equimolar monomer mixture of MEA and EMA. The methoxy protons of the MEA units and the ethoxy protons of EMA units appear at 3.3-3.8 and 3.9$4.2 \mathrm{ppm}$, respectively. Although the rate of copolymerization decreased with an increase in the MEA content in the feed, the copolymers were obtained over the entire range of comonomer composition consistent with the slow homopolymerization of MEA. Figure 6 shows the comonomer-copolymer composition curve for MEA $\left(\mathrm{M}_{2}\right)$-EMA $\left(\mathrm{M}_{1}\right)$ copolymerization. The experimental points fit well to the theoretical curve determined by a non-linear least-squares procedure according to the terminal model. The values of $r_{1}$ and $r_{2}$ were estimated as follows:

$$
r_{1}=2.23 \text { and } r_{2}=0.14
$$

The copolymerization parameters for $\operatorname{MEA}\left(\mathrm{M}_{2}\right)-\operatorname{St}\left(\mathbf{M}_{1}\right)$ copolymerization have already been determined to be $r_{1}=0.82$ and $r_{2}=0.21 .^{25}$

The combination of these values and the $k_{\mathrm{p}}$ values of the respective monomers leads to the cross-propagation rate constants using the $k_{\mathrm{p}}$ instead of the $k_{11}$ or $k_{22}$. 
Table IV. Absolute rate constant of propagation and cross-propagation

\begin{tabular}{|c|c|c|c|c|c|c|}
\hline \multirow{2}{*}{$\mathrm{M}_{1}$} & \multirow{2}{*}{$\mathrm{M}_{2}$} & \multirow{2}{*}{$\frac{k_{11}}{\mathrm{~L} \mathrm{~mol}^{-1} \mathrm{~s}}$} & \multirow{2}{*}{$\frac{k_{12}}{\mathrm{~L} \mathrm{~mol}^{-1} \mathrm{~s}}$} & \multirow{2}{*}{$\frac{k_{21}}{\mathrm{~L} \mathrm{~mol}^{-1} \mathrm{~s}}$} & \multirow{2}{*}{$\frac{k_{22}}{\mathrm{~L} \mathrm{~mol}^{-1} \mathrm{~s}}$} & \multirow{2}{*}{ Ref } \\
\hline & & & & & & \\
\hline $\mathrm{St}$ & MMEA & 330 & 480 & 110 & 19 & 8 \\
\hline St & $\mathrm{M}(\mathrm{DM}) \mathrm{EA}$ & 330 & 570 & 47 & 4.0 & 6 \\
\hline St & M(TE)EA & 330 & 430 & - & - & 9 \\
\hline $\mathrm{St}$ & MMA & 330 & 630 & 1100 & 510 & 27 \\
\hline EMA & MEA & 510 & 230 & 61 & 8.6 & This work \\
\hline MMA & MMEA & 510 & 230 & 43 & 19 & 8 \\
\hline MMA & $\mathrm{M}(\mathrm{DM}) \mathrm{EA}$ & 510 & 140 & 93 & 4.0 & 6 \\
\hline MMA & M(TE)EA & 510 & 6.6 & - & - & 9 \\
\hline
\end{tabular}

$$
k_{12}=k_{11} / r_{1} \quad \text { and } \quad k_{21}=k_{22} / r_{2}
$$

The $k_{\mathrm{p}}$ of MMA instead of EMA was used in calculation because methyl and ethyl ester seems to have similar $k_{\mathrm{p}}$ value. The $k_{\mathrm{p}}$ 's of St and MMA in the literature were employed: $k_{\mathrm{p}}=330 \mathrm{~L} \mathrm{~mol}^{-1} \mathrm{~s}$ for $\mathrm{St}^{26}$ and $k_{\mathrm{p}}=510$ $\mathrm{L} \mathrm{mol}^{-1} \mathrm{~s}$ for MMA at $60^{\circ} \mathrm{C}^{17}$ The $k_{12}$ and $k_{22}$ obtained are summarized in Table IV together with those of other $\alpha$-substituted acrylates.

MEA adds to the poly(St) radical as fast as other $\alpha$ substituted acrylates including MMA. However, addition of the poly(methacrylate) radical to MEA is slightly slower than that of MMA. Furthermore, the poly(MEA) radical is less reactive toward $\mathrm{St}$ than the poly(MMA) radical because of the larger $\alpha$-substituent. It was concluded that monomeric MEA is as reactive as MMEA, M(DM)EA, and MMA in copolymerization and that the steric effect of the $\alpha$-ethyl group provides the reduced reactivity of the poly(MEA) radical which is less reactive than that of the poly(MMA) radical.

\section{REFERENCES AND NOTES}

1. B. Yamada and S. Kobatake, Prog. Polym. Sci., 19, 1089 (1994).

2. B. Yamada, M. Satake, and T. Otsu, Makromol. Chem., 192, 2713 (1991); C. P. Jariwala, P. G. Sundell, C. E. Hoyle, and L. J. Mathias, Macromolecules, 24, 6352 (1991); B. Yamada, M. Satake, and T. Otsu, J. Macromol. Sci.-Pure Appl. Chem., A29, 533 (1992); B. Yamada, S. Kobatake, and S. Aoki, J. Polym. Sci., A, Polym. Chem., 31, 3433 (1993); B. Yamada, S. Tagashira, and T. Otsu, Polym. Bull., 30, 235 (1993); C. P. Jariwala and L. J. Mathias, Macromolecules, 26, 5129 (1993); B. Yamada, S. Kobatake, and S. Aoki, Macromol. Chem. Phys., 195, 933 (1994); R. D. Thompson, T. B. Barclay, K. R. Basu, and L. J. Mathias, Polym. J., 27, 325 (1995).

3. T. Sato, N. Morita, H. Tanaka, and T. Ota, Makromol. Chem., 191, 2599 (1990); T. Sato, I. Kamiya, H. Tanaka, and T. Ota, Eur. Polym. J., 27, 1097 (1991); D. Avci and S. H. Kusefoglu, J. Polym. Sci., A, Polym. Chem., 31, 2941 (1993); D. Avci, S. H. Kusefoglu, R. D. Thompson, and L. J. Mathias, Macromolecules, 27, 1981 (1994); S. Kobatake, B. Yamada, and S. Aoki, Polymer, 36, 413 (1995); T. Sato, I. Kamiya, M. Seno, and H. Tanaka, J. Macromol. Sci.-Pure Appl. Chem., A32, 415 (1995).

4. J. A. Powell and R. K. Graham, J. Polym. Sci., A3, 3451 (1965); B. Yamada and T. Otsu, Makromol. Chem., 192, 333 (1991).

5. T. Sato, S. Inui, H. Tanaka, T. Ota, M. Kamachi, and K. Tanaka, J. Polym. Sci., A, Polym. Chem., 25, 637 (1987); T. Sato, K. Morino, H. Tanaka, and T. Ota, Makromol. Chem., 188, 2951 (1987); T. Sato, Y. Takahashi, M. Seno, H. Nakamura, H. Tanaka, and T. Ota, ibid., 192, 2909 (1991); T. Otsu, K. Yamagishi, and M. Yoshioka, Macromolecules, 25, 2713 (1992);
T. Otsu, K. Yamagishi, A. Matsumoto, M. Yoshioka, and H. Watanabe, ibid., 26, 3026 (1993); T. Sato, Y. Hirose, M. Seno, H. Tanaka, N. Uchiumi, and M. Matsumoto, Eur. Polym. J., 30, 347 (1994).

6. S. Kobatake, B. Yamada, and S. Aoki, Macromol., Rapid Commun., 15, 145 (1994); S. Kobatake and B. Yamada, Macromolecules, 28, 4047 (1995).

7. M. Kudoh, F. Akutsu, Y. Odagawa, K. Naruchi, and M. Miura, Macromol. Chem. Phys., 195, 385 (1994).

8. S. Kobatake and B. Yamada, J. Polym. Sci., A, Polym. Chem., 34, 95 (1996).

9. B. Yamada, S. Kobatake, and O. Konosu, Macromol. Chem. Phys., 197, 901 (1996).

10. K. Chikanishi and T. Tsuruta, Makromol. Chem., 81, 198 (1965).

11. J. Penelle, J. Collot, and G. Rufflard, J. Polym. Sci., A, Polym. Chem., 31, 2407 (1993).

12. A. Matsumoto, K. Mizuta, and T. Otsu, J. Polym. Sci., A, Polym. Chem., 31, 2531 (1993); A. Matsumoto, K. Shimizu, K. Mizuta, and T. Otsu, ibid., 32, 1957 (1994); A. Matsumoto and K. Mizuta, Polym. Bull., 33, 141 (1994).

13. J.-S. Cheng, B. Yamada, and T. Otsu, J. Polym. Sci., A, Polym. Chem., 29, 1837 (1991).

14. R. Kuhn and H. Trischmann, Monatsh. Chem., 95, 457 (1964).

15. B. Yamada, M. Itahashi, and T. Otsu, J. Polym. Sci. Polym. Chem. Ed., 16, 1719 (1978).

16. G. Odian, "Principles of Polymerization," 3rd ed, J. Wiley \& Sons, New York, N.Y., 1991, Chapter 3.

17. T. G. Carswell, D. J. T. Hill, D. I. Londero, J. H. O'Donnell, P. J. Pomery, and C. L. Winzor, Polymer, 33, 137 (1992).

18. W. Fresenius, J. F. K. Huber, E. Pungor, G. A. Rechnitz, W. Simon, and Th. S. West, "Tables of Spectral Data for Structure Determination of Organic Compounds," 2nd ed, Springer, Berlin, 1989, p H215.

19. B. Yamada, S. Tagashira, and S. Aoki, J. Polym. Sci., A, Polym. Chem., 32, 2745 (1994).

20. B. Yamada, K. Toda, and S. Aoki, Polym. Bull., 35, 245 (1995).

21. B. Yamada, S. Kobatake, and T. Otsu, Polym. J., 24, 281 (1992).

22. K. Hatada, T. Kitayama, and E. Masuda, Polym. J., 18, 395 (1986).

23. Because $72 \%$ of the polymer radicals lost activity through disproportionation, the residual $28 \%$ should terminate through combination. Two propagating radicals produce one polymer molecule by combination. Therefore, proportion of disproportionation is estimated to be $72 /[(2 \times 28)+72]=0.56$.

24. G. Moad, E. Rizzardo, D. H. Solomon, and A. L. J. Beckwith, Polym. Bull., 29, 647 (1992); M. Deady, A. W. H. Mau, G. Moad, and T. H. Spurling, Makromol. Chem., 194, 1691 (1993).

25. K. Chikanishi and T. Tsuruta, Makromol. Chem., 81, 211 (1965).

26. B. Yamada, M. Kageoka, and T. Otsu, Polym. Bull., 29, 385 (1992).

27. R. Z. Greenley, "Free Radical Copolymerization Reactivity Ratios," in: "Polymer Handbook," 3rd ed., J. Brandrup and E. H. Immergut, Eds, J. Wiley \& Sons, New York, N.Y., 1989, p II/ 153 . 